\title{
Chronic Ethanol Exposure and Protracted Abstinence Alter NMDA Receptors in Central Amygdala
}

\author{
Marisa Roberto*,', Michal Bajo', Elena Crawford', Samuel G Madamba' and George R Siggins' \\ 'Department of Neuropharmacology, The Scripps Research Institute, La Jolla, CA, USA
}

\begin{abstract}
We recently reported that chronic ethanol treatment (CET) and early withdrawal (2-8 h) altered glutamatergic transmission at both preand postsynaptic sites in central nucleus of the amygdala (CeA). Acute ethanol (44 mM) inhibited the NMDA receptor (NMDAR)mediated EPSCs (NMDA-EPSCs) more in CeA neurons from CET rats than from naïve rats and also decreased paired-pulse facilitation (PPF) of NMDA-EPSCs only in CET rats. To determine whether these CET effects persisted after prolonged withdrawal, we recorded intracellularly in rat CeA slices and measured mRNA and protein expression of CeA NMDAR subunits from CET rats and those withdrawn from ethanol for I or 2 weeks. At I week withdrawal, acute ethanol decreased evoked NMDA-EPSC amplitudes and NMDA currents induced by exogenous NMDA ( 20\%) equally to that in naïe rats, indicating that CET effects on postsynaptic mechanisms reversed I week after CET cessation. However, acute ethanol still decreased PPF of NMDA-EPSCs, indicating that the acute ethanolinduced increase in glutamate release in CeA seen in CET rats was still present at this time. CET also significantly increased mRNA levels of NRI and NR2B NMDAR subunits compared to control rats. At I week withdrawal, mRNA levels for NRI and NR2B subunits were significantly decreased. These changes reversed at 2 weeks withdrawal. In Western blots, a significant increase in protein for all three subunits occurred in CeA from CET rats, but not after I and 2 weeks of withdrawal. These data indicate that CET induces reversible neuroadaptations in synaptic function, gene expression, and protein composition of NMDAR at CeA synapses.

Neuropsychopharmacology (2006) 3 I, 988-996. doi:I0. I038/sj.npp. I 300840; published online 27 July 2005
\end{abstract}

Keywords: alcohol; electrophysiology; real-time PCR; ethanol dependence; paired-pulse facilitation; Western blot

\section{INTRODUCTION}

NMDA receptors (NMDARs) are heteromeric ligand-gated ion channels composed of an obligatory NR1 subunit and combinations of NR2 and sometimes NR3 subunits (CullCandy et al, 2001; Sutula et al, 1998). The NR2 subunits include NR2A-D that confer specific functional properties to NMDARs (Cull-Candy et al, 2001; Monyer et al, 1994).

NMDARs are important sites of ethanol action (Carter et al, 1995; Lovinger et al, 1989) and are thought to mediate, in part, ethanol dependence, tolerance, and withdrawal (Darstein et al, 2000; Eckardt et al, 1998; Kalluri et al, 1998; Krystal et al, 1998; Narita et al, 2000). It has been demonstrated that NR2A- and NR2B-containing NMDARs are the most sensitive to ethanol (Allgaier, 2002; Lovinger, 1995; Masood et al, 1994; Mirshahi and Woodward, 1995). Although the molecular mechanisms remain to be elucidated, there is a broad consensus that acute ethanol inhibits

\footnotetext{
* Correspondence: Dr M Roberto, Department of Neuropharmacology, The Scripps Research Institute, 10550 N. Torrey Pines Rd., CVN- 12, La Jolla, CA 92037, USA, Tel: + I 858784 7262, Fax: + I 858784 7393, E-mail: mroberto@scripps.edu

Received 28 March 2005; revised I 3 June 2005; accepted I 6 June 2005 Online publication: 21 June 2005 at http://www.acnp.org/citations/ Npp062105050207/default.pdf
}

NMDARs (Calton et al, 1998; Criswell et al, 2003; Hoffman et al, 1989; Kumari and Ticku, 2000; Loftis and Janowsky, 2003; Lovinger et al, 1989; Nie et al, 1994; Martin et al, 1995; Tabakoff and Hoffman, 1996; Tsai and Coyle, 1998; Woodward, 1999; Roberto et al, 2004b), whereas chronic ethanol treatment (CET) leads to a compensatory upregulation of these receptors resulting in increased NMDARmediated function after removal of ethanol (Gulya et al, 1991; Nagy et al, 2004). This increase in NMDARs, and especially the NR2B subunit, may contribute to the ethanol withdrawal syndrome (Kumari and Ticku, 2000; Nagy et al, 2004; Narita et al, 2000; Ripley and Little, 1995; Thomas et al, 1998) that is characterized by both behavioral and electrophysiological parameters (Macey et al, 1996).

The withdrawal syndrome starts immediately after the cessation of alcohol exposure and corresponds to a detoxification associated with hyperexcitability. A more severe withdrawal phase develops within $24 \mathrm{~h}$ of the cessation of alcohol exposure, can last for several days, and leads to neuropathological changes (Becker et al, 1997; Collins et al, 1996; Fadda and Rossetti, 1998; Maier and Pohorecky, 1989; Zou et al, 1996). Rodents show increased or rebound drinking (analogous to a relapse in humans) following prolonged forced abstinence from a period of alcohol self-administration, and such a rebound or relapse 
becomes even more profound with the development of dependence. Although dependence is characterized by the appearance of a withdrawal syndrome after cessation of alcohol use, relapse can occur even weeks after withdrawal signs have ceased, suggesting that neuroadaptive changes occurring during dependence can persist beyond the withdrawal period itself. Relapse, that is, a rebound selfadministration, may be maximal at 1-2 weeks during abstinence (Roberts et al, 2000).

We recently reported (Roberto et al, 2004b) that CET and early withdrawal (2-8h) led to neuroadaptations in NMDA receptor-mediated excitatory postsynaptic potentials and currents (NMDA-EPSP/Cs) at both pre- and postsynaptic sites in the central nucleus of the amygdala (CeA), a brain nucleus thought to be intimately involved in ethanol dependence (Koob and Le Moal, 2001). We found that acute ethanol-induced inhibition of NMDA-EPSP/Cs was enhanced in CeA of CET compared to naïve rats. With local applications of NMDA, acute ethanol inhibited NMDA currents more in slices taken from chronic ethanol-treated rats than in those of naïve rats, suggesting that CET sensitizes NMDARs to ethanol. Interestingly, the NR2Bselective antagonist ifenprodil completely occluded the acute ethanol inhibition of NMDA-EPSP/Cs, suggesting that the ethanol effect was mediated by NR2B subunits. In addition, acute ethanol reduced paired-pulse facilitation (PPF) of EPSCs only in the CeA of CET rats but not of naïve rats, indicating a facilitatory presynaptic effect of acute ethanol on glutamate release (Roberto et al, 2004b). Since CET caused changes in NMDAR-mediated synaptic transmission in $\mathrm{CeA}$, in the present study, we have now replicated our previous findings (Roberto et al, 2004b) and determined whether the effects induced by CET persist after the cessation of CET, by recording from CeA neurons of animals withdrawn from CET for 1 and 2 weeks. We also examined the effects of CET and withdrawal on the expression of mRNA coding for NR1, NR2A, and NR2B subunits in CeA using real-time PCR. In addition, we assessed protein levels of NR1, NR2A, and NR2B subunits in CeA from CET and withdrawn rats using Western blots.

Our combined results indicate that chronic ethanol and withdrawal lead to neuroadaptations of synaptic glutamatergic transmission that are associated with changes in NMDAR subunit expression in CeA. Furthermore, these findings support the hypothesis that glutamatergic synapses in CeA play an important role in ethanol dependence.

\section{MATERIALS AND METHODS}

\section{Slice Preparation}

We prepared amygdala slices as previously described (Roberto et al, 2003; Roberto et al, 2004a) from male Sprague-Dawley rats (150-300 g; 4-7 weeks old) that were anesthetized with halothane (3\%) and decapitated. We rapidly removed the brains into ice-cold artificial cerebrospinal fluid (ACSF) gassed with $95 \% \mathrm{O}_{2}$ and $5 \% \mathrm{CO}_{2}$. Transverse slices $400 \mu \mathrm{m}$ thick were cut on a Vibratome Series 3000 (Technical Products International, St Louis, $\mathrm{MO})$, incubated in an interface configuration for about $30 \mathrm{~min}$, and then completely submerged and continuously superfused (flow rate of $2-4 \mathrm{ml} / \mathrm{min}$ ) with warm $\left(31^{\circ} \mathrm{C}\right.$ ), gassed ACSF of the following composition in $\mathrm{mM}: \mathrm{NaCl}$, 130; KCl, 3.5; $\mathrm{NaH}_{2} \mathrm{PO}_{4}, 1.25 ; \mathrm{MgSO}_{4} \cdot 7 \mathrm{H}_{2} \mathrm{O}, 1.5 ; \mathrm{CaCl}_{2}, 2.0$; $\mathrm{NaHCO}_{3}, 24$; glucose, 10. In studies of the NMDARmediated responses, we used a modified ACSF containing reduced $\mathrm{Mg}^{2+}$ levels $(0.75 \mathrm{mM})$. The inner chamber had a total volume of $0.8 \mathrm{ml}$; at the $2-4 \mathrm{ml} / \mathrm{min}$ superfusion rates used, $90 \%$ replacement of the chamber solution could be obtained within $1 \mathrm{~min}$. Drugs were added to the ACSF from stock solutions to obtain known concentrations in the superfusate.

\section{Chronic Ethanol Treatment}

We used the standard ethanol inhalation method, in use for over 25 years, of The Scripps Research Institute and Alcohol Research Center for developing chronic ethanol-treated (CET) rats (Roberto et al, 2004a, b; Rogers et al, 1979). All procedures were conducted in accordance with the National Institutes of Health Guide for the Care and Use of Laboratory Animals. Briefly, male Sprague-Dawley rats were housed 2-4 per cage with a 0600-1800 hours light cycle and with free access to food and water. The animals were randomly divided into two groups and placed into either ethanol vapor chambers or into air-only chambers (sham naive controls). In the ethanol-treated group, we exposed rats to continuous ethanol vapors for at least 2 weeks. The health of the animals, weight gain, food and water intake, body posture, and locomotor activity were monitored daily. Sham controls were treated similarly but without exposure to ethanol vapor. As we found no statistically significant $(p>0.1)$ differences in the basic electrophysiological measures or ethanol responses between neurons from naïve control and sham control rats, we pooled measures from these two groups. On experiment days, animals in the CET group were maintained in the ethanol vapor chamber until preparation of the amygdala slices. We made recordings in ethanol-free ACSF from slices of CET rats 2-8 h after cutting the slices as previously described (Roberto et al, 2004b). Since long-term chronic ethanol exposure has been shown to produce changes in synaptic transmission that persist after ethanol withdrawal (Nagy et al, 2004; Peris et al, 1997), we determined whether changes in NMDA responses were present after a prolonged withdrawal period defined as prolonged abstinence ( 1 and 2 weeks of ethanol withdrawal). Therefore, animals withdrawn from ethanol for 1 or 2 weeks were maintained in identical chambers as the CET and control animals, but were not exposed to ethanol vapor during the withdrawal period leading to the experimental day.

\section{Blood Alcohol Level (BAL) and Body Weight}

We determined BALs of the CET animals from tail-blood samples taken three times per week. Control animals were also routinely bled. When necessary, we adjusted the ethanol vapor concentration after BAL measurement to achieve a constant target BAL of $150-200 \mathrm{mg} / \mathrm{dl}$. The mean BAL of all CET animals was $177.4 \pm 10 \mathrm{mg} / \mathrm{dl}(n=26)$. The CET animals did not show signs of deteriorating health, impairment of locomotor activity, or abnormality in body posture and gait. The mean body weight of CET animals was $255 \pm 9 \mathrm{~g}(n=23)$, compared to a mean body weight of 
$270 \pm 12 \mathrm{~g}(n=10)$ for sham control animals. The mean body weight of 1 week and 2 week withdrawn animals were $290 \pm 14 \mathrm{~g}(n=12)$ and $319 \pm 20 \mathrm{~g}(n=12)$, respectively.

\section{Electrophysiology}

We recorded from CeA neurons with sharp micropipettes $(3 \mathrm{M} \mathrm{KCl})$ using discontinuous voltage- or current-clamp mode. In voltage-clamp, we used a switching frequency of $3-5 \mathrm{kHz}$ and, on a separate oscilloscope, continuously monitored electrode settling time and capacitance neutralization at the headstage. Data were acquired with an Axoclamp-2A preamplifier (Axon Instruments, Foster City, CA) and stored for later analysis using pClamp software (Axon Instruments, Foster City, CA). We evoked pharmacologically isolated NMDAR-mediated excitatory postsynaptic potentials and currents (NMDAR-EPSP/Cs) by stimulating locally within the $\mathrm{CeA}$ through a bipolar stimulating electrode in low $\mathrm{Mg}^{2+}(0.75 \mathrm{mM}$ instead of $1.5 \mathrm{mM})$ ACSF containing $30 \mu \mathrm{M}$ bicuculline, $1 \mu \mathrm{M}$ CGP $55845 \mathrm{~A}$, and $10 \mu \mathrm{M}$ 6-cyano-7-nitroquinoxaline-2,3-dione (CNQX).

We held the cells near their resting membrane potential (RMP; mean: $-76 \mathrm{mV}$ ) and applied hyperpolarizing and depolarizing current steps $(200 \mathrm{pA}$ increments, $750 \mathrm{~ms}$ duration) to generate voltage-current $(V / I)$ curves. We examined PPF in each neuron using $100 \mathrm{~ms}$ interstimulus intervals (Roberto et al, 2004b). The stimulus strength was adjusted such that the amplitude of the first EPSP/C was $50 \%$ of maximal determined in an input/output (I/O) relationship. We calculated the PPF ratio as the second EPSP/C amplitude over that of the first EPSP/C. We took all measures before ethanol superfusion (control), during ethanol (5-10 $\mathrm{min})$, and following ethanol washout (20$30 \mathrm{~min}$ ). We express all values as mean \pm SEM. We subjected data to a between-subjects ANOVA or within-subject ANOVA with repeated measures (eg, for electrophysiological measures within the same group of neurons before and during subsequent treatment conditions) and, when appropriate, to the Newman-Keuls post hoc test, with $p<0.05$ considered statistically significant. In some cases, we also used Student's paired or unpaired $t$-test.

\section{NMDA Pressure Application}

We applied NMDA (10 $\mathrm{mM}$ in the pipette) locally near the recorded neuron by pressure from a pipette (tip diameter, 2-4 $\mu \mathrm{m}$; pressure $1-20 \mathrm{psi}$; duration, $0.5-3 \mathrm{~s}$ ). Resulting NMDA currents were recorded in voltage-clamp mode in low $\mathrm{Mg}^{2+}$ ACSF containing $1 \mu \mathrm{M}$ CGP 55845A, $30 \mu \mathrm{M}$ bicuculline, $10 \mu \mathrm{M}$ CNQX, and $1 \mu \mathrm{M}$ TTX (to minimize presynaptic effects). The neurons were held near their RMPs (mean: $-76 \mathrm{mV}$ ). After stable NMDA currents were achieved, we took peak current measurements at several time points before, during, and after ethanol application. We defined an ethanol effect on NMDA currents as a $10 \%$ or greater inhibition of peak response (Roberto et al, 2004b).

\section{Drugs}

CGP 55845A was a gift from Norvartis Pharma. We purchased D-AP5 and CNQX from Tocris Cookson (Holloway
Road, MO), bicuculline and NMDA from Sigma (St Louis, MO), TTX from Calbiochem (San Diego, CA), and ethanol from Remet (La Mirada, CA). To avoid loss of ethanol by evaporation, the solutions were diluted in gassed ACSF from sealed stock solutions of reagent grade $95 \%$ ethyl alcohol in water immediately before administration.

\section{Quantitative PCR}

For quantification of mRNA levels of the tested NMDAR subunits in CeA, we used naïve $(n=6)$, CET $(n=6), 1$ week $(n=4)$ - and 2 week $(n=4)$-ethanol-withdrawn rats. We isolated $\mathrm{CeA}$ from brain slices prepared as described above. The samples were stored at $-80^{\circ} \mathrm{C}$ until use. We carried out isolation of RNA, including DNase treatment, and synthesis of cDNA with the absolutely RNA RT-PCR Miniprep Kit and ProSTAR $^{\mathrm{TM}}$ First-Strand RT-PCR Kit (Stratagene, USA), respectively. Real-time PCR was performed with the LightCycler System (Roche, Switzerland) and using SYBR Green I dye. To prepare samples for real-time PCR, we used FastStart DNA Master SYBR Green I kit (Roche, Switzerland). The primers used in the study were: NR1: $5^{\prime}$ agatggccctgtcag tgtgt $3^{\prime}$ and $5^{\prime}$ gtgaagtggtcgttgggagt $3^{\prime}$; NR2A: $5^{\prime}$ gtgatcgtgctgaac aagga3 ${ }^{\prime}$ and $5^{\prime}$ gctcgcagtcagaaaaggac $3^{\prime}$; NR2B: $5^{\prime}$ tccgaagctggtg ataatcc $3^{\prime}$ and $5^{\prime}$ tggtcatcctcttgctcctc $3^{\prime} ; \beta$-actin: $5^{\prime}$ ggctcctagcacc atgaaga $3^{\prime}$ and $5^{\prime}$ cagtgaggccaggatagagc $3^{\prime}$.

We set the thermal cycle program to $94^{\circ} \mathrm{C}$ for $10 \mathrm{~min}, 40$ amplification cycles consisting of $95^{\circ} \mathrm{C}$ for $10 \mathrm{~s}, 58^{\circ} \mathrm{C}$ for $5 \mathrm{~s}$, and $72^{\circ} \mathrm{C}$ for $14 \mathrm{~s}$ steps, followed by one step creating a melting curve. Melting curve analysis (SoFAR software) and agarose gel electrophoresis were carried out to analyze the amplicons obtained. Both techniques showed a single product after amplification of all of the tested subunits as well as $\beta$-actin (data not shown). For a determination of CT (Cycle threshold) values, we used SoFar software (Wilhelm et al, 2003). We did relative quantification of the tested NMDAR subunits using the comparative CT method $(\Delta \Delta \mathrm{CT})$. We performed statistical analysis using Student's $t$-test (statistical significance: $p<0.05$ ).

\section{Western Blotting}

We determined protein levels of the NMDAR subunits in the control and CET rats (six rats per group). CeA was isolated as described above. Brain tissue was homogenized manually in buffer $(10 \mathrm{mM}$ Tris- $\mathrm{HCl}, \mathrm{pH} 7.5,2 \%$ SDS, Complete Mini Protease Cocktail Inhibitor (Roche, Switzerland)) and boiled at $100^{\circ} \mathrm{C}$ for $3 \mathrm{~min}$. Supernatants obtained by centrifugation at $4000 \mathrm{~g}$ for $10 \mathrm{~min}$ were subsequently used for measurement of protein concentration (BCA protein assay reagent kit, Pierce, USA) as well as for further analysis.

We performed electrophoresis and transfer of proteins with the NuPAGE ${ }^{\circledR}$ System (Invitrogen, USA). We separated 7.5 ( $\beta$-actin) and 15 (NMDAR subunits) $\mu$ g of protein/ lane of the brain homogenate on $12 \%$ NuPAGE ${ }^{\mathbb{R}}$ Bis-Tris gels $\left(\beta\right.$-actin) and $7 \%$ NuPAGE ${ }^{\circledR}$ Tris-Acetate gels (NMDAR subunits; Invitrogen, USA), respectively, and transferred them onto Invitrolon PVDF membrane (Invitrogen, USA). The optimal NMDAR subunit concentration of $15 \mu \mathrm{g} / \mathrm{lane}$ used in this study was determined by testing several concentrations: $10,15,20$, and $25 \mu \mathrm{g}$ of protein/lane. The 
specific antibodies were rabbit anti-NMDAR1 affinity-purified polyclonal antibody (dilution $0.75 \mu \mathrm{g} / \mathrm{ml}$ ), rabbit antiNMDAR2A affinity-purified polyclonal antibody $(1: 4250)$, rabbit anti-NMDAR2B affinity-purified polyclonal antibody $(1: 1300)$ (AB1516, $A B 1555$ and $\mathrm{AB} 1557 \mathrm{P}$, respectively, Chemicon, USA), and rabbit polyclonal antibody to $\beta$-actin $(1: 5600)$ (ab8227, Novus Biologicals, USA) and followed by secondary antibody: goat anti-rabbit $\operatorname{IgG}(\mathrm{H}+\mathrm{L})(1: 5000)$ coupled to horseradish peroxidase (Southern Biotechnology Associates, Inc., USA). For visualization, we used Western Lightning TM (Perkin-Elmer Life Sciences, Inc., USA) and measured densities of immunoreactive bands by NIH Image 1.63. We expressed the results as arbitrary units corresponding to the subunit/ $\beta$-actin ratio of the individual samples.

a
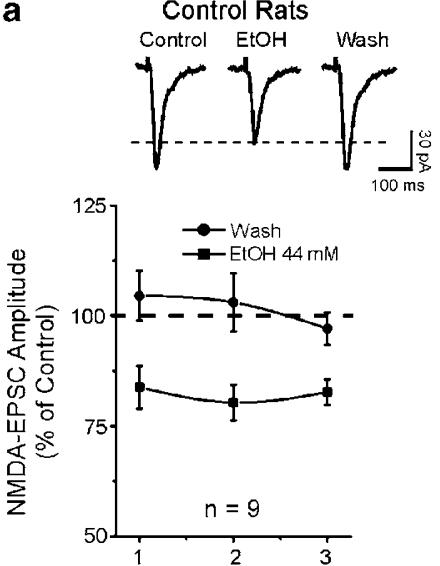

Normalized Stimulus Strength

c

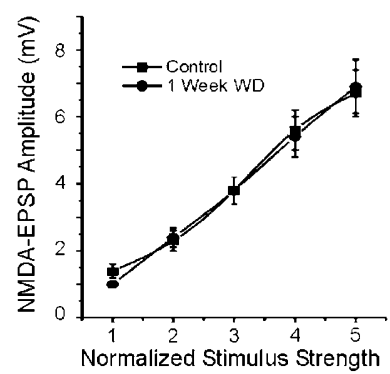

e
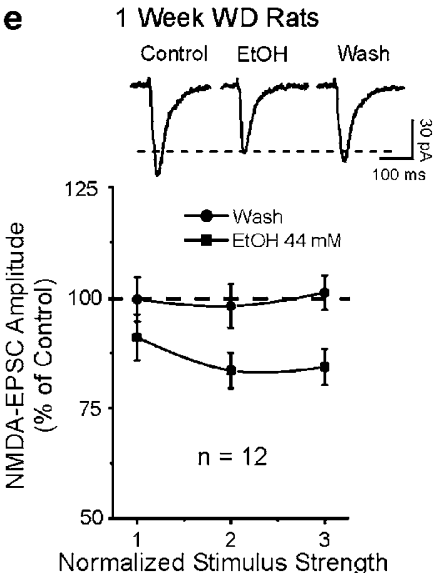
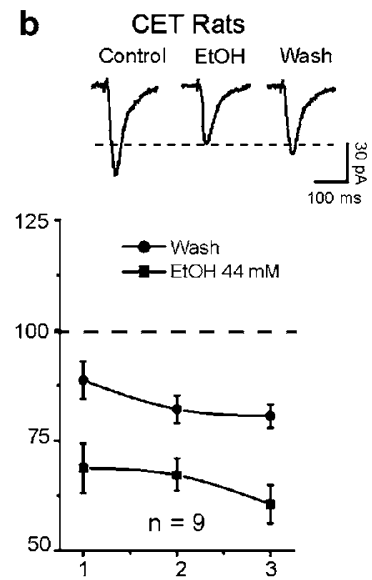

Normalized Stimulus Strength
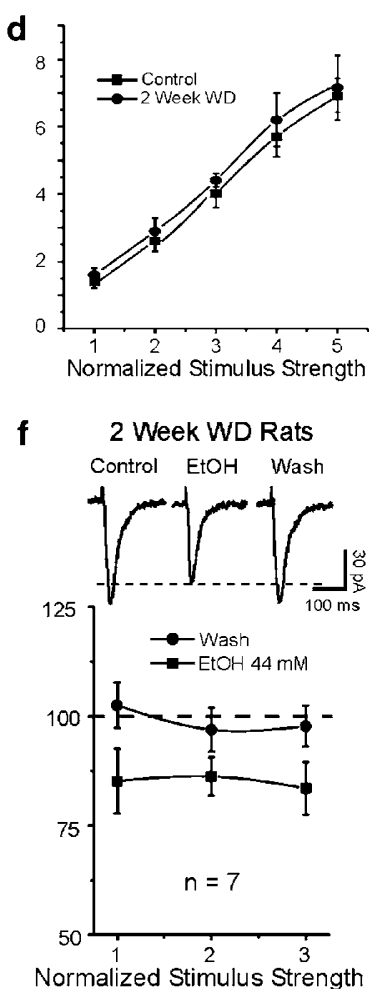

\section{RESULTS}

\section{Electrophysiological Studies}

Recovery of ethanol effects on NMDA-EPSCs after prolonged abstinence. Previously, we found that the depressant effect of acute ethanol on NMDA-EPSP/C amplitudes was significantly stronger in CeA neurons from CET rats than in those from naïve rats (Roberto et al, 2004b). From the dose-response curves, ethanol at a concentration of $44 \mathrm{mM}$ produced the maximal inhibition; therefore, we used that dose throughout the present study. Here, $44 \mathrm{mM}$ ethanol significantly decreased (to $82 \%$; mean across three different stimulus intensities; $n=9$ ) evoked NMDA-EPSCs (Figure 1a) in CeA neurons of naïve rats, as we reported previously (Roberto et al, 2004b). In CeA neurons from CET rats, acute ethanol inhibited evoked NMDA-EPSC amplitudes to a greater degree (to 65\%; mean across three different stimulus intensities; $n=9$ ) than in neurons from control rats (Figure 1b), again as reported previously (Roberto et al, 2004b).

To determine the persistence of the effects of chronic ethanol, in the present study, CET animals were withdrawn from the ethanol vapors for 1 or 2 weeks prior to preparing the slices. We recorded from $70 \mathrm{CeA}$ neurons that had a mean RMP of $-76 \pm 2 \mathrm{mV}$ and a mean input resistance of $109 \pm 5 \mathrm{M} \Omega$. In contrast to hippocampus (Ripley and Little, 1995), in CeA neurons we did not observe signs of postsynaptic neuronal hyperexcitability, such as prolonged depolarizations or spontaneous burst discharges, at this time of withdrawal. In fact, we did not observe a significant difference between the baseline NMDA-EPSP input-output curves generated by equivalent stimulus intensities in neurons from CET rats or rats withdrawn either 1 (Figure 1c) or 2 (Figure 1d) weeks compared to those from age-matched naive rats. Ethanol $44 \mathrm{mM}$ superfused for 7-10 min significantly $(p<0.05)$ decreased the amplitude of NMDA-EPSCs by the same amount (10-17\%) in CeA neurons from both 1 week- $(n=12$; Figure 1e) and 2 weekwithdrawn rats $(n=6$; Figure $1 \mathrm{f})$, with recovery after ethanol washout ( $15 \mathrm{~min})$. This effect is equivalent to that

Figure I Acute application of ethanol decreases the amplitude of evoked NMDA-EPSCs in CeA neurons. (a) Top panel: Representative NMDA-EPSC recordings in a CeA neuron from a control rat. Bottom panel: In CeA neurons from naïve rats, superfusion of $44 \mathrm{mM}$ ethanol significantly $(P<0.05, n=9)$ reduced the mean evoked NMDA-EPSCs by 15-20\% over all the stimulus strengths used, with recovery on washout. (b) Top panel: NMDA-EPSC recordings in a CeA neurons from a CET rat. Bottom panel: In CeA neurons from CET rats, acute ethanol ( $44 \mathrm{mM})$ reduced (by 35-42\%) mean NMDA-EPSC amplitudes to a greater extent ( $n=9 ; p<0.05$ compared to baseline; $p<0.05$ compared to control rats) than in neurons from naïve rats, suggesting sensitization to acute ethanol. (c, d): Baseline $1 / O$ curves of evoked NMDA-EPSP amplitudes are comparable in CeA neurons from control $(n=12)$ and either I week (c; $n=10)$ and 2 weeks (d; $n=7)$ ethanol withdrawn (WD) rats. (e) Top panel: Representative recordings of NMDA-EPSCs in a CeA slice from a I week-WD rat recorded before, during, and after superfusion of $44 \mathrm{mM}$ ethanol. Bottom panel: Pooled data, superfusion of ethanol significantly $(p<0.05, n=12)$ decreased the mean NMDA-EPSC amplitudes in I week-withdrawn CeA neurons. (f) Top panel: NMDA-EPSC recordings in a CeA neuron from a 2 week-ethanol withdrawn rat. Bottom panel: Acute ethanol significantly $(p<0.05, n=7)$ increased mean NMDA-EPSC amplitudes, with recovery on ethanol washout $(20 \mathrm{~min})$. 
in control rats (Figure 1a; also Roberto et al, 2004b). Acute ethanol had no significant $(p>0.1)$ effect on basic membrane properties such as membrane potential, input resistance, or spike amplitude (not shown), in agreement with our previous findings (Roberto et al, 2003; Roberto et al, 2004a,b). In the neurons taken from 1 week-withdrawn rats, acute ethanol significantly $(p<0.05 ; n=10)$ decreased the evoked non-NMDA EPSCs by $18 \pm 5 \%$ of control, similar to the ethanol effect in neurons taken from naïve rats (not shown).

In neurons from CET rats, acute ethanol inhibited evoked NMDA-EPSC amplitudes to a greater degree than in neurons from control rats (Figure 1b), concomitant with a decreased PPF (Figure 2b, see also Roberto et al, 2004b) suggestive of an increase in glutamate release. This was supported by our previous microdialysis studies showing that intra-CeA administration of ethanol increased dialysate glutamate content in CET rats (Roberto et al, 2004b). To determine whether the inhibitory effect of acute ethanol on NMDA-EPSCs involved presynaptic changes in glutamate release, and whether or not these changes persist over prolonged withdrawal, we examined PPF in CeA neurons before, during, and after ethanol application. We found that baseline PPF of NMDA-EPSCs in neurons from 1 and 2 week-withdrawn animals was similar (respectively, PPF ratio $=1.44 \pm 0.08, n=12$; PPF ratio $1.45 \pm 0.04, n=6)$ and not significantly different $(p>0.01)$ from that of control rats

a
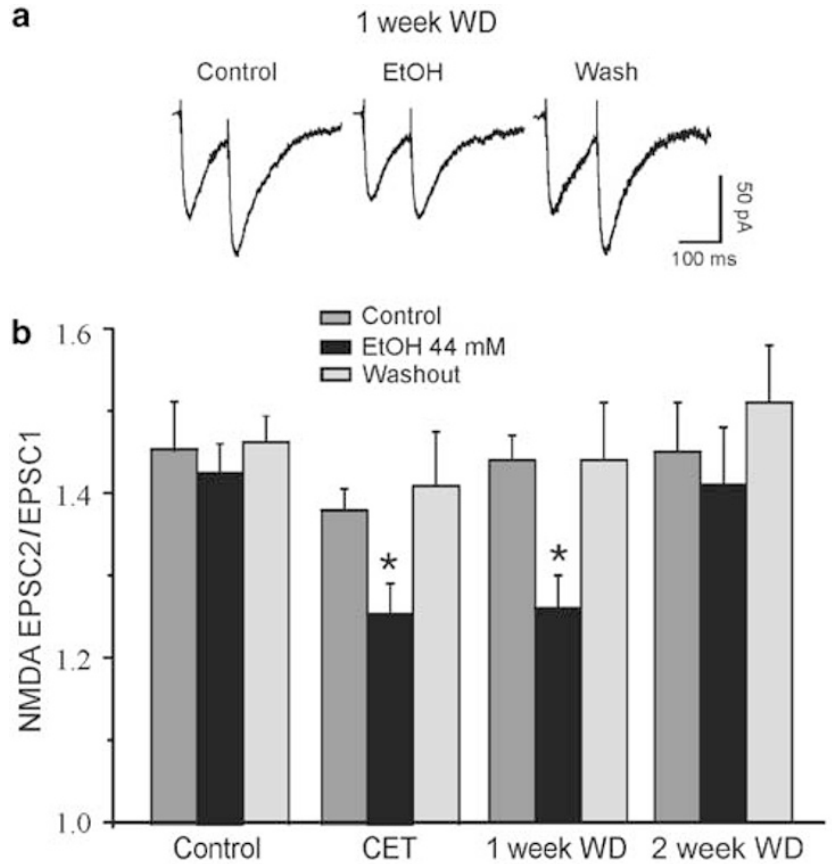

Figure 2 Baseline PPF is unchanged in CeA neurons after CET and protracted withdrawal from CET, and acute $44 \mathrm{mM}$ ethanol decreases PPF of NMDA-EPSCs only after CET and I week withdrawal. (a) Current records of NMDA-EPSCs in response to two stimuli $100 \mathrm{~ms}$ apart in a neuron from I week-ethanol-withdrawn (WD) rat. Acute ethanol reduced the PPF ratio. (b) Pooled data of PPF ratios expressed as the second EPSC amplitude over the first. Superfusion of ethanol did not alter PPF ratio in control rats $(n=9)$, but significantly decreased the PPF ratio in neurons from CET (by II\%; * $p<0.05 ; n=9$ ) and I week (by I4\%; $* p<0.05$; $n=12$ ) rats. In CeA neurons from 2 week-withdrawn rats, ethanol had no effect on PPF ratio $(n=7)$, suggesting a recovery of its presynaptic effect.
$(\mathrm{PPF}$ ratio $=1.46 \pm 0.05, n=10$; Figure $2 \mathrm{~b})$. Superfusion of $44 \mathrm{mM}$ ethanol onto control neurons had little effect on PPF of NMDA-EPSCs (Figure $2 \mathrm{~b}$ and see also Roberto et al, $2004 b)$, but significantly $(p<0.05)$ decreased PPF of NMDAEPSCs in neurons from 1 week-withdrawn rats (Figure $2 \mathrm{a}$, b). Similarly, acute $44 \mathrm{mM}$ ethanol also significantly $(p<0.05)$ decreased PPF of both compound glutamatergic (isolated only by bicuculline and CGP 55845A) and nonNMDA (isolated by APV, bicuculline, and CGP 55845A) EPSCs by $15 \%$ in CeA neurons from 1 week-withdrawn rats (not shown), again indicating that the acute ethanolinduced increase in glutamate release persisted after 1 week of withdrawal from CET. This presumed presynaptic effect returned to control levels after 2 weeks of withdrawal (Figure 2b) when acute ethanol did not alter PPF of NMDAEPSCs. The CET-induced downregulation of non-NMDA EPSPs (Roberto et al, 2004b) was also reversed to control levels after 1 week withdrawal (data not shown).

Our past studies showed that the depressant effect of acute $44 \mathrm{mM}$ ethanol on responses to locally applied NMDA (in the presence of TTX) was greater in CeA neurons from CET (to $47 \pm 7 \%$ of control) compared to naïve (to $70 \pm 5 \%$ of control) rats (Roberto et al, 2004b). Here, we first duplicated this finding and then estimated whether this change continues after protracted withdrawal (Figure 3).

a
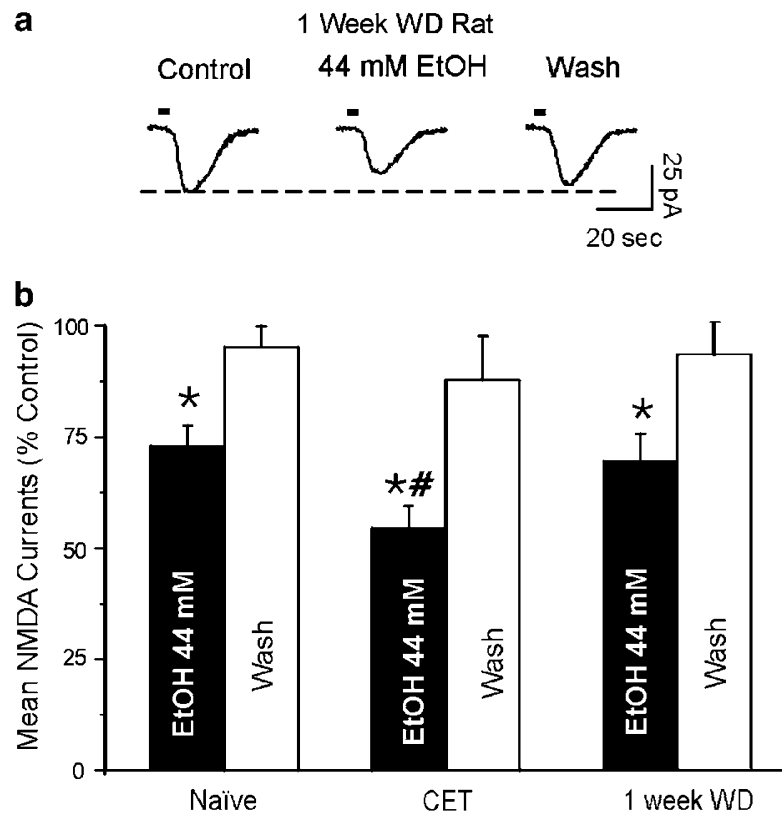

Figure 3 Inward currents elicited by local application of NMDA are decreased by acute ethanol. (a) Representative current records before, during, and after ethanol superfusion from a CeA neuron of a I weekwithdrawn (WD) rat. The bars above the records indicate the local pressure application of NMDA ( $10 \mathrm{mM}$ in the pipette). (b) In CeA neurons from CET rats, $44 \mathrm{mM}$ ethanol more strongly decreased mean NMDA currents (by $54 \pm 5 \%$; $* p<0.00$ I compared to baseline, $\# p<0.05$ compared to ethanol induced decrease in control neurons). In four neurons from I week-WD rats, $44 \mathrm{mM}$ ethanol decreased NMDA currents to the same extent (by $31 \pm 7 \%$ ) as in control rats. Local pressure application $(2 \mathrm{~s} ; 6 \mathrm{psi})$ of NMDA (10 mM in the pipette; applied every $2 \mathrm{~min}$ ) in low $\mathrm{Mg}^{2}+$ ACSF containing GABAergic blockers, CNQX and I $\mu \mathrm{M}$ TTX. In four neurons from naïve rats, superfusion of $44 \mathrm{mM}$ ethanol $(5-10 \mathrm{~min})$ significantly $(* p<0.05)$ decreased NMDA-induced currents by $27 \pm 5 \%$, with recovery on washout (10-15 min). 
We superfused ethanol $(44 \mathrm{mM})$ after obtaining a stable baseline of exogenous NMDA-induced currents (10$15 \mathrm{~min})$. The depressant effect of acute ethanol on NMDA currents was significantly $(p<0.05)$ stronger (to $54 \pm 5 \%)$ in neurons from CET rats (Figure 3) than in those from control rats (to $73 \pm 5 \%$ of control; $n=4$ ). Ethanol elicited an inhibition of the NMDA currents in CeA neurons from 1 week-withdrawn rats (to $69 \pm 6 \% ; n=3 ; p<0.05$ ) similar to that in control rats (Figure 3), suggesting that this ethanol effect at the postsynaptic level was totally recovered after 1 week cessation of CET.

\section{Molecular Biology Studies}

Chronic ethanol and withdrawal alter expression of NMDAR subunits in CeA. To correlate the alterations caused by CET on NMDAR-mediated transmission in the CeA with gene expression of NMDAR subunits, we studied mRNA for NR1, NR2A, and NR2B, the most ethanolsensitive subunits. CET significantly $(p<0.05)$ augmented NR1 (to $139 \%$ of control; Figure $4 a$ ) and NR2B (to $184 \%$; Figure 4c) subunit mRNA levels in CeA, with a nonsignificant tendency to augment mRNA levels for NR2A (to $125 \%$; Figure $4 \mathrm{~b}$ ). By contrast, the NR1 and NR2B mRNA levels were significantly $(p<0.05)$ reduced 1 week following
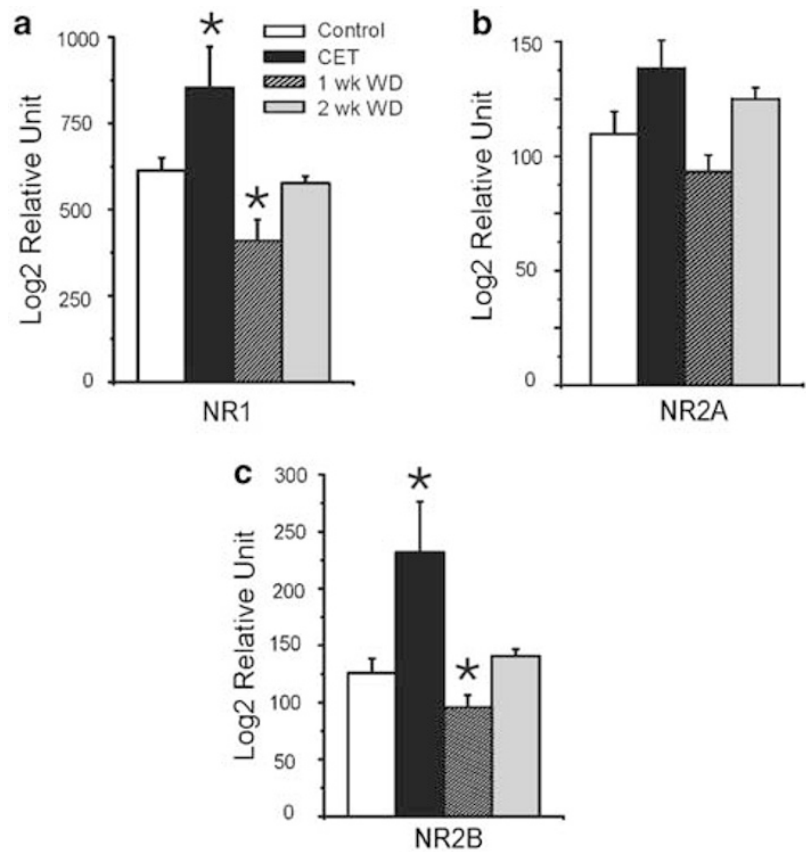

Figure 4 CET alters the expression of NMDA receptor subunits in rat CeA tissue. Summary of real-time PCR of the mRNA coding NR subunits in four different groups (controls, CET rats, I week and 2 week withdrawal). (a) The mean mRNA level for the NRI subunit is significantly increased in CeA from CET $(n=6)$ rats and significantly decreased in I weekwithdrawn $(n=5)$ rats when compared with that from controls $(n=6)$. In $\mathrm{CeA}$ from 2 week-withdrawn $(n=4)$ rats, the mean level of mRNA for NRI was comparable to those from control rats. (b) Pooled data on the effect of CET, I and 2 week withdrawal on mRNA coding for the NR2A subunit in the same groups of rats as in (a). CET has a non-significant trend to enhance the level of mRNA for NR2A in CeA. (c) The mRNA levels for the NR2B subunit is significantly increased in CET rats and is significantly decreased in I week-ethanol-withdrawn rats as compared to controls. The asterisk denotes statistical significance $(p<0.05)$.
CET and returned to control levels at 2 weeks of ethanol withdrawal (Figure 4a,c).

Chronic ethanol and withdrawal alter protein levels of NMDAR subunits. To further analyze NMDAR subunit composition, we used Western blotting to measure NR1, NR2A, and NR2B proteins from CeA of control, CET, 1 and 2 week-withdrawn rats. We found that the levels of all three subunits were significantly increased in CeA of CET rats (Figure 5a-d) compared to control rats. However, the protein levels for all three subunits returned to control values after 1 week of ethanol withdrawal (Figure 5a-c). These data suggest that there is an upregulation of NR1, $\mathrm{NR} 2 \mathrm{~A}$, and NR2B in CeA as a result of CET that may account for some of the changes found in the electrophysiological studies (see above and Roberto et al, 2004b).

\section{DISCUSSION}

We previously showed that acute and chronic ethanol significantly alter CeA glutamatergic transmission, involving both pre- and postsynaptic sites (Roberto et al, 2004b). In the present study, we have replicated these findings. Furthermore, using electrophysiology and molecular biology we examined whether these alterations in NMDARmediated transmission persisted after protracted ethanol withdrawal and whether they were associated with changes in gene and protein expression of NR2A and NR2B

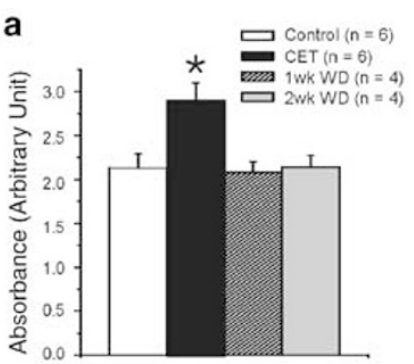

NR1

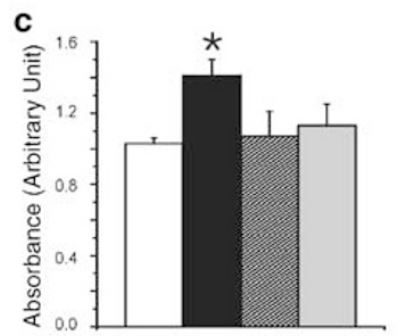

NR2B b

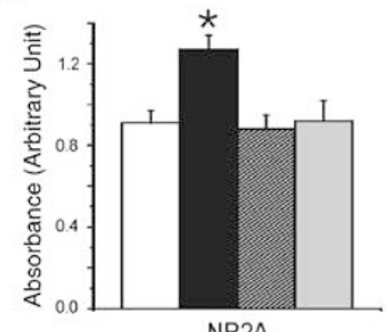

NR2A

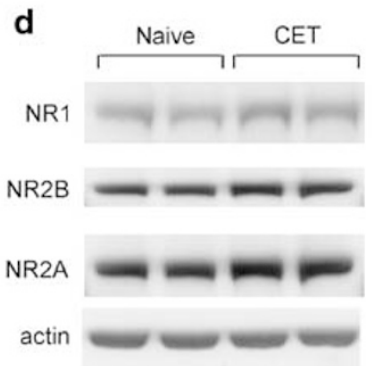

Figure 5 CET increases protein levels of NRI, NR2A, and NR2B subunits. (a) In CeA of CET rats, the NRI protein level is significantly $(2.9 \pm 0.2 ; p<0.05 ; n=6)$ enhanced compared with that from naive $(2.13 \pm 0.1 ; n=6)$ rats. NRI proteins at I week $(2.08 \pm 0.1 ; n=4)$ and 2 week $(2.14 \pm 0.1 ; n=4)$ withdrawal are not different from that of naive rats. CET increased the NR2A (b; $1.27 \pm 0.01$ and $0.91 \pm 0.01$, in CET and naive rats, respectively), and $N R 2 B(c ; 1.41 \pm 0.09$ vs $1.03 \pm 0.03$ ) protein levels in the same four groups of rats, with nearly complete recovery at I and 2 weeks of ethanol withdrawal. Protein levels are expressed as arbitrary units obtained by normalization of NMDA receptor subunits against $\beta$-actin. (d) Representative Western blots for NRI, NR2A, NR2B subunits, and $\beta$-actin. 
subunits, the most ethanol-sensitive NMDAR subunits (Allgaier, 2002; Lovinger, 1995; Mirshahi and Woodward, 1995). We found that in CeA neurons from 1 weekwithdrawn rats, acute ethanol decreased both the evoked NMDA-EPSC amplitudes and postsynaptic NMDA currents to the same extent as in naïve rats, suggesting that these CET-induced effects recovered within 1 week of cessation of CET. In CeA of 1 week 'abstinent' rats, acute ethanol still decreased the PPF of NMDA-EPSCs, indicating the ethanol effect at the presynaptic level persisted at this time of withdrawal. However, acute ethanol did not alter PPF in neurons from 2 week-withdrawn rats. Our molecular data suggests that the electrophysiological effects of CET are correlated with a direct effect of chronic ethanol on NMDAR subunit expression at both mRNA and protein levels. In CeA from CET rats, we found a significant increase in the mRNA coding for the NR1 and NR2B subunits. In addition, there was a significant upregulation of all three subunit proteins in CeA from CET rats. Our preliminary immunohistochemical observations of the subunits also support the hypothesis that these neuronal NMDAR subunits are increased after CET (unpublished observations). At 1 week of withdrawal, mRNA levels for NR1 and NR2B subunits were significantly decreased, perhaps rebounding as an allostatic response to the CET, but the protein levels for the three subunits were similar to controls. At 2 week withdrawal, mRNA levels also had returned to control values.

NMDARs are a major site of ethanol action, and dependence, tolerance, and withdrawal symptoms may be mediated in part by NMDARs. A prominent electrophysiological effect of acute ethanol is a decrease in current generated by NMDAR activation (Criswell and Breese, 2005; Criswell et al, 2003; Fadda and Rossetti, 1998; Kalluri et al, 1998; Lovinger, 2002; Lovinger et al, 1989; Nie et al, 1994; Roberto et al, 2004b; Tabakoff and Hoffman, 1996; Tsai and Coyle, 1998; Woodward, 2000; Yang et al, 1996). The sensitivity of NMDAR channels to ethanol is dependent on the NR2 subunit expressed: for example, NMDARs with NR1/2A and NR1/2B subunits are the most sensitive to ethanol (Allgaier, 2002; Lovinger, 1995; Mirshahi and Woodward, 1995). In contrast to mature hippocampus and cortex where NR1/NR2A subunits predominate (Chavis and Westbrook, 2001; Okabe et al, 1998; Scheetz and Constantine-Paton, 1994; Tovar and Westbrook, 1999), in the CeA, the NMDARs are composed mainly of NR1/NR2B subunits and with little or no developmental change in subunit composition (Lopez de Armentia and Sah, 2003).

Prolonged ethanol exposure induces neuroadaptations at the cellular and subcellular levels in the brain that appear to counter the acute effects of ethanol. These adaptations can lead to prolonged or permanent changes in the structure and function of neurons. There is growing evidence that CET causes alterations in NMDAR subunit levels and composition (Chen et al, 1999; Dettmer et al, 2003; Kalluri et al, 1998; Kumari and Ticku, 2000; Snell et al, 1996; Thomas et al, 1998; Trevisan et al, 1994; Winkler et al, 1999) that could lead to changes in synaptic transmission at glutamatergic synapses. We previously reported that prolonged ethanol caused an increased sensitivity of postsynaptic NMDARs and of presynaptic glutamate release to acute ethanol in CeA (Roberto et al, 2004b). We hypothesized that CET might perturb expression of NMDAR subunits in CeA to increase ethanol sensitivity via enhanced expression of the subunits most sensitive to ethanol. In accord with this idea, in the present study we have replicated and extended our electrophysiological study using real-time PCR and Western blot analysis to show that mRNA for NR1 and NR2B subunits and NR1, NR2A, and NR2B proteins are significantly increased in CET rats compared to controls.

Our data are consistent with other reports that CET increases the mRNA levels of these subunits in rat cerebral cortex and hippocampus (Follesa and Ticku, 1996; Kalluri et al, 1998; Narita et al, 2000) for at least $9 \mathrm{~h}$ after chronic ethanol, with total recovery by 2 days of withdrawal (Kalluri et al, 1998; Narita et al, 2000). Our previous findings that the NR2B subunit-selective antagonist ifenprodil was more effective in inhibiting NMDA-EPSCs and in occluding the acute ethanol effect in CET rats than in naive rats (Roberto et al, 2004b) further supports the upregulation of NR2B subunits after CET. In addition, the higher NMDAR sensitivity to ethanol and ifenprodil after CET, or perhaps rapid NMDA internalization (Roberto et al, 2004b), may account for the lack of recovery after acute ethanol washout. Importantly, the NMDA component affected by ethanol was ifenprodil-sensitive, suggesting the specific involvement of NR2B-containing NMDARs in the effect of acute ethanol. To determine if CET perhaps redistributed the NR subunit proteins differentially across the subregions of the CeA, we have preliminarily examined the NMDAR proteins at the cellular level using immunohistochemical staining of NR1, NR2A, and NR2B subunits. We found no apparent differences in regional subunit distribution, but a visible increase in the number of positive cell bodies staining for all the subunits, but especially NR2B, in the CeA of the CET rats as compared to control rats (unpublished observations).

Although we found increased protein levels for the NR1, $\mathrm{NR} 2 \mathrm{~A}$, and NR2B subunits in CeA from CET rats compared to naïve rats, we did not observe significant changes in the baseline NMDAR-mediated synaptic transmission (eg I/O curves, see Figure 1) after CET. The effects of CET on NMDARs are likely to be complex and include not only alterations in gene transcription/translation but also posttranslational adaptations (eg, phosphorylation, internalization) that may be distinct for each subunit and may compensate for the neuroadaptations of NMDAR subunit protein. We speculate that rapid changes in NMDARs such as phosphorylation-dependent alterations in channel conductance and/or surface expression (Miyakawa et al, 1997; Yaka et al, 2003) could be involved in the acute effect of ethanol, and slower changes such as alterations in subunit synthesis and/or synaptic localization may occur during chronic ethanol. Interestingly, prolonged ethanol has been found to increase the size and density of both the NR1 and NR2B subunit clusters at synaptic $v s$ extrasynaptic localizations in cultured hippocampal neurons (Carpenter-Hyland et al, 2004). However, the exact molecular mechanisms responsible for adaptive upregulation of NMDAR complexes in response to long-term ethanol exposure remain to be determined.

Many neuroadaptations induced by chronic ethanol appear to persist after ethanol has cleared from the brain. 
Therefore, we investigated whether or not those changes seen in CeA persisted after prolonged ethanol withdrawal for 1 and 2 weeks. We chose these times because behaviorally they represent a period of protracted abstinence after which voluntary ethanol intake is significantly enhanced (Roberts et al, 2000). The inhibition by acute ethanol of evoked NMDA-EPSCs and NMDA currents were comparable in CeA neurons from naïve and both 1 and 2 week-withdrawn rats, suggesting that the cellular sensitization of NMDARs to ethanol recorded in CET rats had recovered. However, at 1 week of ethanol withdrawal, acute ethanol still decreased the PPF of NMDA-EPSCs, suggesting that the facilitatory presynaptic effect of ethanol on glutamate release persists at this withdrawal time; this effect recovered at 2 weeks ethanol withdrawal. Although we do not yet know the mechanisms involved, our data suggest that chronic ethanol differentially affects the pre- and postsynaptic sites of acute ethanol action, and that the alterations in acute ethanol-sensitivity of the presynaptic release machinery for glutamate are more persistent. Future studies using microdialysis will further investigate this persistent presynaptic ethanol effect. Interestingly, the magnitude of the increase in NR polypeptide levels observed in CET rats was comparable to the increase in the mRNA levels of these subunits. By contrast, at 1 week ethanol withdrawal, the mRNA levels for NR1 and NR2B were downregulated, yet the protein levels did not diminish below control levels at the same stage, suggesting that mRNA levels may have compensated by producing spare receptors during CET. It is tempting to speculate that the significant rebound reduction of mRNA at 1 week withdrawal drove the relatively rapid recovery of the respective protein levels.

Overall, our findings support the hypothesis that ethanol dependence and withdrawal are associated with neuroadaptations in glutamatergic transmission in the CeA. These data suggest that CET induces a consistent upregulation of NR1, NR2A, and NR2B subunits in CeA that accounts for the changes found in NMDAR-mediated transmission at these synapses. Finally, because some of these neuroadaptations are long lasting, they may also play a role in the development of neuronal compensatory (allostatic) processes involved in the rebound drinking following protracted abstinence.

\section{ACKNOWLEDGEMENTS}

We thank Drs FE Bloom, GF Koob, SJ Henriksen, and PJ Kenny for critical comments on the manuscript, and Drs W Fröstl and A Suter (Novartis Pharma) for CGP-55854A. This study was supported by grants from NIH: AA013517 (NIAAA-Funded Integrative Neuroscience Initiative on Alcoholism (INIA)), AA12294 (INIA), AA013521 (INIA), AA06420, and DA03665.

\section{REFERENCES}

Allgaier C (2002). Ethanol sensitivity of NMDA receptors. Neurochem Int 41: 377-382.

Becker HC, Diaz-Granados JL, Hale RL (1997). Exacerbation of ethanol withdrawal seizures in mice with a history of multiple withdrawal experience. Pharmacol Biochem Behav 57: 179-183.
Calton JL, Wilson WA, Moore SD (1998). Magnesium-dependent inhibition of $N$-methyl-D-aspartate receptor-mediated synaptic transmission by ethanol. J Pharmacol Exp Ther 287: 1015-1019.

Carpenter-Hyland EP, Woodward JJ, Chandler LJ (2004). Chronic ethanol induces synaptic but not extrasynaptic targeting of NMDA receptors. J Neurosci 24: 7859-7868.

Carter AJ, Bechtel WD, Grauert M, Harrison P, Merz H, Stransky W (1995). BIII $277 \mathrm{CL}$ is a potent and specific ion-channel blocker of the NMDA receptor-channel complex. J Pharmacol Exp Ther 275: 1382-1389.

Chavis P, Westbrook G (2001). Integrins mediate functional preand postsynaptic maturation at a hippocampal synapse. Nature 411: 317-321.

Chen X, Moore-Nichols D, Nguyen H, Michaelis EK (1999). Calcium influx through NMDA receptors, chronic receptor inhibition by ethanol and 2-amino-5-phosponopentanoic acid, and receptor protein expression. J Neurochem 72: 1969-1980.

Collins MA, Corso TD, Neafsey EJ (1996). Neuronal degeneration in rat cerebrocortical and olfactory regions during subchronic 'binge' intoxication with ethanol: possible explanation for olfactory deficits in alcoholics. Alcohol Clin Exp Res 20: 284-292.

Criswell HE, Breese GR (2005). Effects of alcohol on ion channels in brain-a new look. In: Preedy VR, Watson RR (eds). Comprehensive Handbook of Alcohol Related Pathology, Chapter 67. Elsevier: London. pp 855-869.

Criswell HE, Ming Z, Griffith BL, Breese GR (2003). Comparison of effect of ethanol on $N$-methyl-D-aspartate- and GABA-gated currents from acutely dissociated neurons: absence of regional differences in sensitivity to ethanol. J Pharmacol Exp Ther 304: 192-199.

Cull-Candy S, Brickley S, Farrant M (2001). NMDA receptor subunits: diversity, development and disease. Curr Opin Neurobiol 11: 327-335.

Darstein MB, Landwehrmeyer GB, Feuerstein TJ (2000). Changes in NMDA receptor subunit gene expression in the rat brain following withdrawal from forced long-term ethanol intake. Naunyn Schmiedebergs Arch Pharmacol 361: 206-213.

Dettmer TS, Barnes A, Iqbal U, Bailey CD, Reynolds JN, Brien JF et al (2003). Chronic prenatal ethanol exposure alters ionotropic glutamate receptor subunit protein levels in the adult Guinea pig cerebral cortex. Alcohol Clin Exp Res 27: 677-681.

Eckardt MJ, File SE, Gessa GL, Grant KA, Guerri C, Hoffman PL et al (1998). Effects of moderate alcohol consumption on the central nervous system. Alcohol Clin Exp Res 22: 998-1040.

Fadda F, Rossetti ZL (1998). Chronic ethanol consumption: from neuroadaptation to neurodegeneration. Prog Neurobiol 56: $385-431$

Follesa P, Ticku MK (1996). Chronic ethanol-mediated upregulation of the $N$-methyl-D-aspartate receptor polypeptide subunits in mouse cortical neurons in culture. J Biol Chem 271: 13297-13299.

Gulya K, Grant KA, Valverius P, Hoffman PL, Tabakoff B (1991). Brain regional specificity and time-course of changes in the NMDA receptor-ionophore complex during ethanol withdrawal. Brain Res 547: 129-134.

Hoffman PL, Rabe CS, Moses F, Tabakoff B (1989). N-methyl-Daspartate receptors and ethanol: inhibition of calcium flux and cyclic GMP production. J Neurochem 52: 1937-1940.

Kalluri HS, Mehta AK, Ticku MK (1998). Up-regulation of NMDA receptor subunits in rat brain following chronic ethanol treatment. Brain Res Mol Brain Res 58: 221-224.

Koob GF, Le Moal M (2001). Drug addiction, dysregulation of reward, and allostasis. Neuropsychopharmacology 24: 97-129.

Krystal JH, Petrakis IL, Webb E, Cooney NL, Karper LP, Namanworth S et al (1998). Dose-related ethanol-like effects of the NMDA antagonist, ketamine, in recently detoxified alcoholics. Arch Gen Psychiatry 55: 354-360. 
Kumari M, Ticku MK (2000). Regulation of NMDA receptors by ethanol. Prog Drug Res 54: 152-189.

Loftis JM, Janowsky A (2003). The $N$-methyl-D-aspartate receptor subunit NR2B: localization, functional properties, regulation, and clinical implications. Pharmacol Ther 97: 55-85.

Lopez de Armentia M, Sah P (2003). Development and subunit composition of synaptic NMDA receptors in the amygdala: NR2B synapses in the adult central amygdala. J Neurosci 23: 6876-6883.

Lovinger DM (1995). Developmental decrease in ethanol inhibition of $\mathrm{N}$-methyl-D-aspartate receptors in rat neocortical neurons: relation to the actions of ifenprodil. J Pharmacol Exp Ther 274: 164-172.

Lovinger DM (2002). NMDA receptors lose their inhibitions. Nat Neurosci 5: 614-616.

Lovinger DM, White G, Weight FF (1989). Ethanol inhibits NMDAactivated ion current in hippocampal neurons. Science 243: 1721-1724.

Macey DJ, Schulteis G, Heinrichs SC, Koob GF (1996). Timedependent quantifiable withdrawal from ethanol in the rat: effect of method of dependence induction. Alcohol 13: 163-170.

Maier DM, Pohorecky LA (1989). The effect of repeated withdrawal episodes on subsequent withdrawal severity in ethanol-treated rats. Drug Alcohol Depend 23: 103-110.

Martin D, Tayyeb MI, Swartzwelder HS (1995). Ethanol inhibition of AMPA and kainate receptor-mediated depolarizations of hippocampal area CA1. Alcohol Clin Exp Res 19: 1312-1316.

Masood K, Wu C, Brauneis U, Weight FF (1994). Differential ethanol sensitivity of recombinant $N$-methyl-D-aspartate receptor subunits. Mol Pharmacol 45: 324-329.

Mirshahi T, Woodward JJ (1995). Ethanol sensitivity of heteromeric NMDA receptors: effects of subunit assembly, glycine and NMDAR1 $\mathrm{Mg}(2+)$-insensitive mutants. Neuropharmacology 34: 347-355.

Miyakawa T, Yagi T, Kitazawa H, Yasuda M, Kawai N, Tsuboi K et al (1997). Fyn-kinase as a determinant of ethanol sensitivity: relation to NMDA-receptor function. Science 278: 698-701.

Monyer H, Burnashev N, Laurie DJ, Sakmann B, Seeburg PH (1994). Developmental and regional expression in the rat brain and functional properties of four NMDA receptors. Neuron 12: 529-540.

Nagy GG, Watanabe M, Fukaya M, Todd AJ (2004). Synaptic distribution of the NR1, NR2A and NR2B subunits of the $N$ methyl-D-aspartate receptor in the rat lumbar spinal cord revealed with an antigen-unmasking technique. Eur J Neurosci 20: 3301-3312.

Narita M, Soma M, Mizoguchi H, Tseng L, Suzuki T (2000). Implications of the NR2B subunit-containing NMDA receptor localized in mouse limbic forebrain in ethanol dependence. Eur J Pharmacol 401: 191-195.

Nie Z, Madamba SG, Siggins GR (1994). Ethanol inhibits glutamatergic neurotransmission in nucleus accumbens neurons by multiple mechanisms. J Pharmacol Exp Ther 271: 1566-1573.

Okabe S, Collin C, Auerbach JM, Meiri N, Bengzon J, Kennedy MB et al (1998). Hippocampal synaptic plasticity in mice overexpressing an embryonic subunit of the NMDA receptor. J Neurosci 18: 4177-4188.

Peris J, Eppler B, Hu M, Walker DW, Hunter BE, Mason $\mathrm{K}$ et al (1997). Effects of chronic ethanol exposure on GABA receptors and $\mathrm{GABAB}$ receptor modulation of $3 \mathrm{H}-\mathrm{GABA}$ release in the hippocampus. Alcohol Clin Exp Res 21: 1047-1052.

Ripley T, Little HJ (1995). Effects on ethanol withdrawal hyperexcitability of chronic treatment with a competitive $N$-methyl-D-aspartate receptor antagonist. J Pharmacol Exp Ther 272: 112-118.

Roberto M, Madamba SG, Moore SD, Tallent MK, Siggins GR (2003). Ethanol increases GABAergic transmission at both pre- and postsynaptic sites in rat central amygdala neurons. Proc Natl Acad Sci USA 100: 2053-2058.

Roberto M, Madamba SG, Stouffer DG, Parsons LH, Siggins GR (2004a). Increased GABA release in the central amygdala of ethanol-dependent rats. J Neurosci 24: 10159-10166.

Roberto M, Schweitzer P, Madamba SG, Stouffer DG, Parsons LH, Siggins GR (2004b). Acute and chronic ethanol alter glutamatergic transmission in rat central amygdala: an in vitro and in vivo analysis. J Neurosci 24: 1594-1603.

Roberts AJ, Heyser CJ, Cole M, Griffin P, Koob GF (2000). Excessive ethanol drinking following a history of dependence: animal model of allostasis. Neuropsychopharmacology 22: 581-594.

Rogers J, Wiener SG, Bloom FE (1979). Long-term ethanol administration methods for rats: advantages of inhalation over intubation or liquid diets. Behav Neural Biol 27: 466-486.

Scheetz AJ, Constantine-Paton M (1994). Modulation of NMDA receptor function: implications for vertebrate neural development. FASEB J 8: 745-752.

Snell LD, Nunley KR, Lickteig RL, Browning MD, Tabakoff B, Hoffman PL (1996). Regional and subunit specific changes in NMDA receptor mRNA and immunoreactivity in mouse brain following chronic ethanol ingestion. Brain Res Mol Brain Res 40: 71-78.

Sutula T, Zhang P, Lynch M, Sayin U, Golarai G, Rod R (1998). Synaptic and axonal remodeling of mossy fibers in the hilus and supragranular region of the dentate gyrus in kainate-treated rats. J Comp Neurol 390: 578-594.

Tabakoff B, Hoffman PL (1996). Alcohol addiction: an enigma among us. Neuron 16: 909-912.

Thomas MP, Monaghan DT, Morrisett RA (1998). Evidence for a causative role of $\mathrm{N}$-methyl-D-aspartate receptors in an in vitro model of alcohol withdrawal hyperexcitability. J Pharmacol Exp Ther 287: 87-97.

Tovar KR, Westbrook GL (1999). The incorporation of NMDA receptors with a distinct subunit composition at nascent hippocampal synapses in vitro. J Neurosci 19: 4180-4188.

Trevisan L, Fitzgerald LW, Brose N, Gasic GP, Heinemann SF, Duman RS et al (1994). Chronic ingestion of ethanol upregulates NMDAR1 receptor subunit immunoreactivity in rat hippocampus. J Neurochem 62: 1635-1638.

Tsai G, Coyle JT (1998). The role of glutamatergic neurotransmission in the pathophysiology of alcoholism. Annu Rev Med 49: 173-184.

Wilhelm J, Pingoud A, Hahn M (2003). SoFAR: software for fully automatic evaluation of real-time PCR data. Bio Techniques 34: 324-332.

Winkler A, Mahal B, Kiianmaa K, Zieglgansberger W, Spanagel R (1999). Effects of chronic alcohol consumption on the expression of different NR1 splice variants in the brain of AA and ANA lines of rats. Brain Res Mol Brain Res 72: 166-175.

Woodward JJ (1999). Ionotropic glutamate receptors as sites of action for ethanol in the brain. Neurochem Int 35: 107-113.

Woodward JJ (2000). Ethanol and NMDA receptor signaling. Crit Rev Neurobiol 14: 69-89.

Yaka R, Tang KC, Camarini R, Janak PH, Ron D (2003). Fyn kinase and NR2B-containing NMDA receptors regulate acute ethanol sensitivity but not ethanol intake or conditioned reward. Alcohol Clin Exp Res 27: 1736-1742.

Yang X, Criswell HE, Simson P, Moy S, Breese GR (1996). Evidence for a selective effect of ethanol on $N$-methyl-D-aspartate responses: ethanol affects a subtype of the ifenprodil-sensitive $\mathrm{N}$-methyl-D-aspartate receptors. J Pharmacol Exp Ther 278: 114-124.

Zou JY, Martinez DB, Neafsey EJ, Collins MA (1996). Binge ethanol-induced brain damage in rats: effect of inhibitors of nitric oxide synthase. Alcohol Clin Exp Res 20: 1406-1411. 